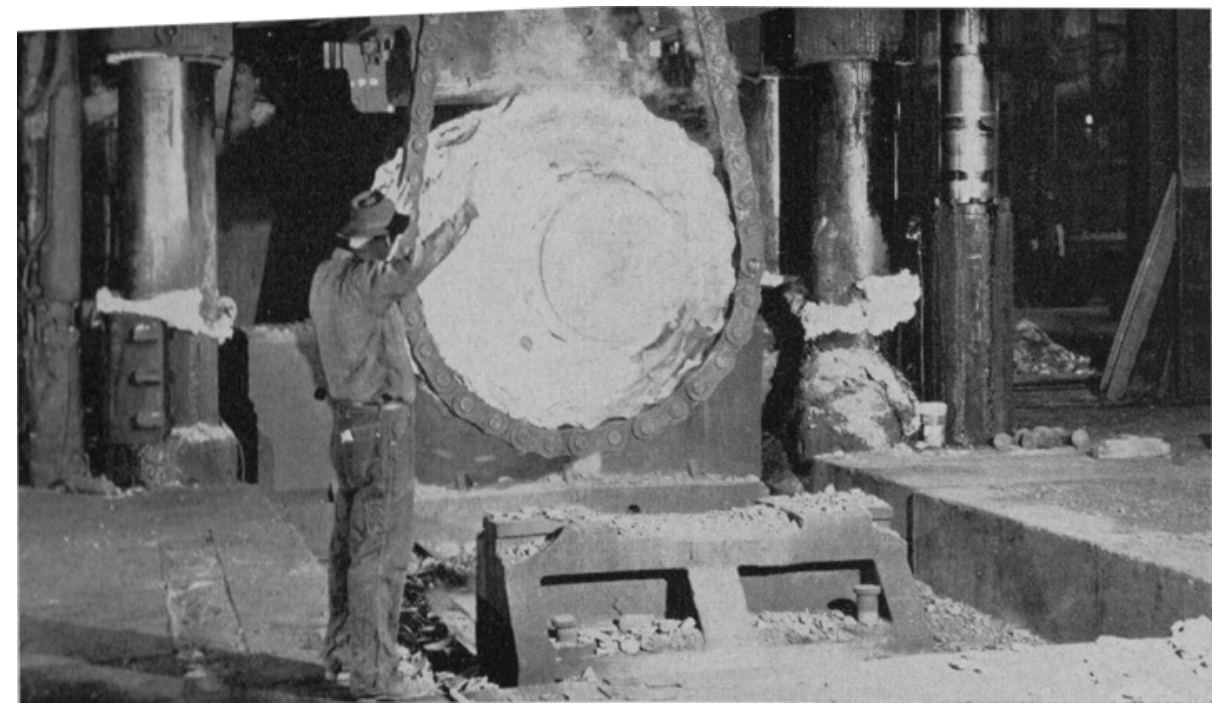

Initial operation in fabricating the rotor disk from a 92-in. ingot takes place in the 7500ton forging press at the Bethlehem, $\mathrm{Pa}_{\text {., }}$ plant of Bethlehem Steel Co. Ingot mold corrugations are still visible.

\title{
Bethlehem Forges Giant Rotor Disks
}

B

ETHLEHEM STEEL CO. is forging 11 giant rotor disks to be used for compressors in supersonic wind tunnels to be employed by the NACA for experimental air development. The disks are approximately $18 \mathrm{ft}$ in diam, $9 \mathrm{in}$. thick, and weigh almost 50 tons. The disks are being forged from 92-in. ingots, and delivered in heat treated and rough machined condition. The diameter of the forgings and the tioning of the forging under the 7500 -ton press required partial forging of two disks simultaneously to avoid unequal loading of the press. One of the largest heat treatment furnaces in the nation is being used in the operation. The rotor discs are wider and heavier than those forged at the Bethlehem plant for the Columbia University and University
of Chicago Cyclotrons.

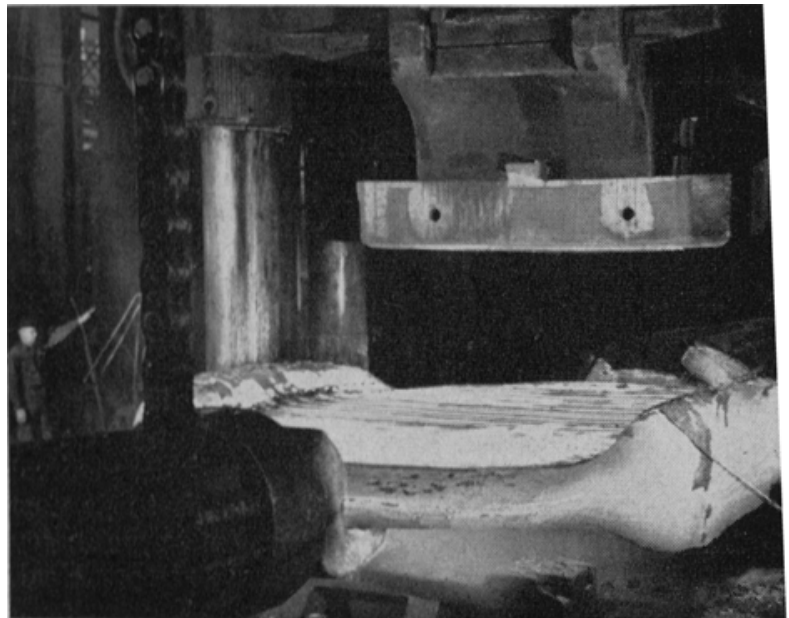

The greater part of the piece is finished to required thickness in a lengthwise path during this stage of the forging. Lips are left on each side because of the limited spreod of the press columns, preventing forging the entire piece to exact thickness. Piece was returned for reheating. The lost operotion reduced lips to thickness.

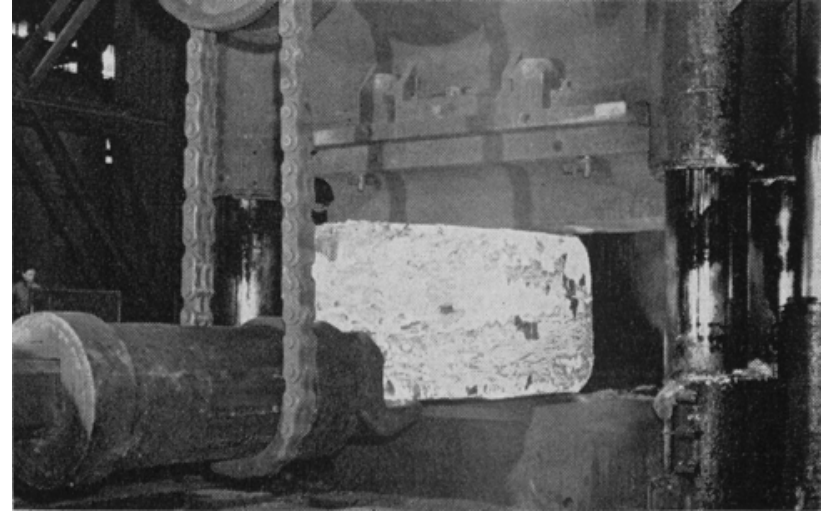

At this point the ingot has been cropped and upset. Its diameter is being compressed and grain refined by kneading action of the press.

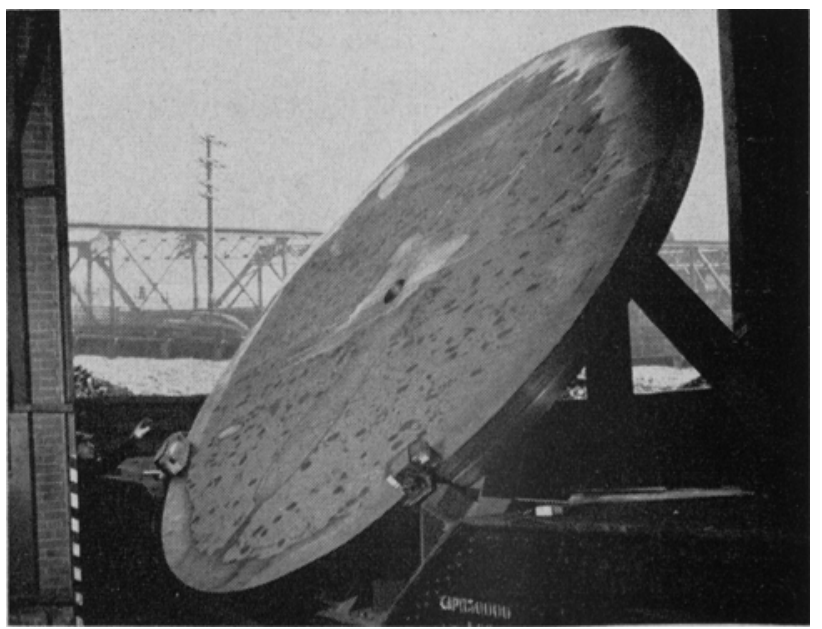

The $18 \mathrm{ft}$ diam forging could not be transported from shop to shop by ordinary means, necessitating a specially rigged railway car permitting it to be tilted. The rotor disk was heat treated and rough mochined at the Bethlehem plant before being shipped to the NACA. Materials handling problem was one of the most serious encountered. 